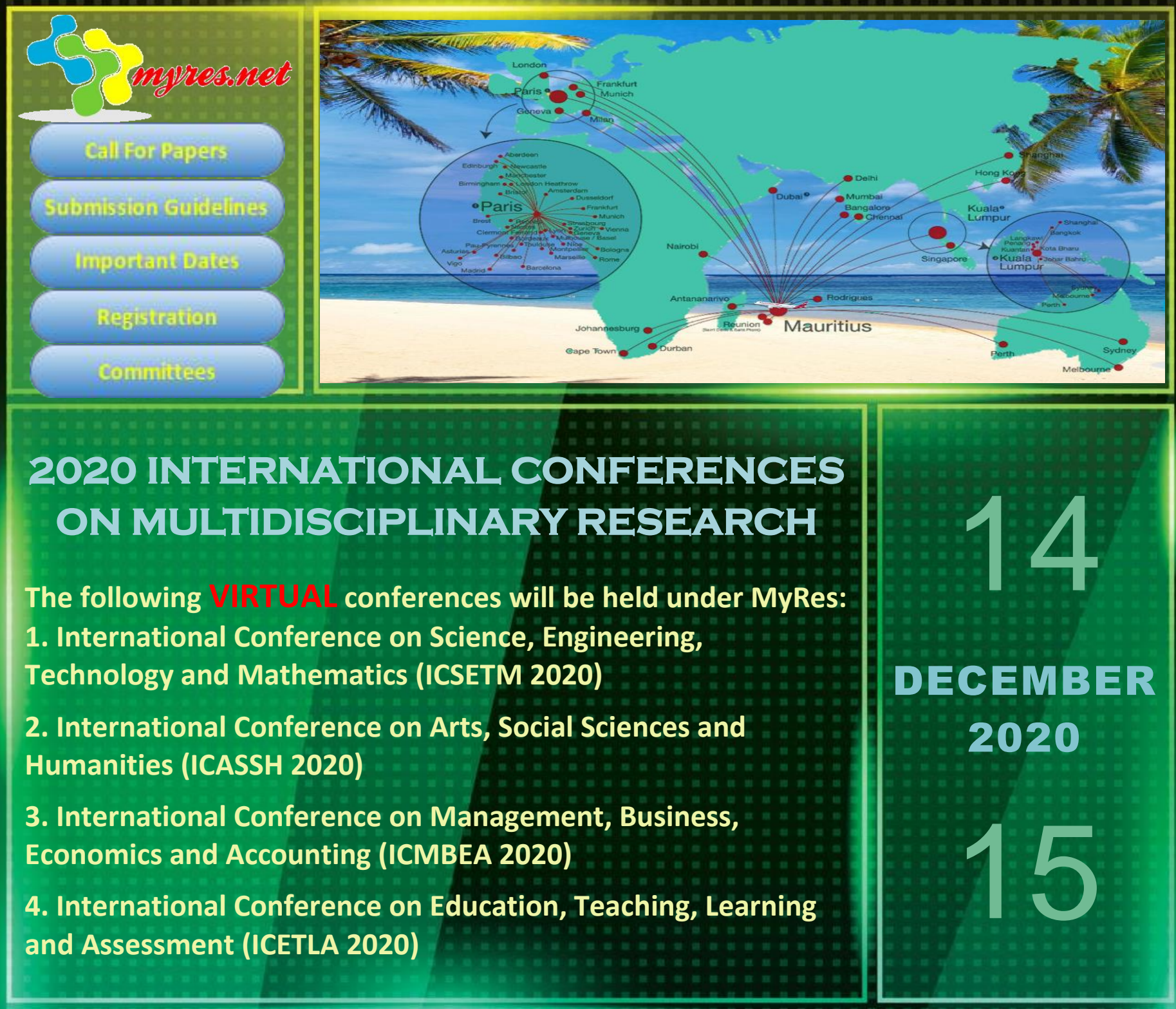

\title{
https://www.myres.net
}

Voila Hotel, Bagatelle, Mola, Mauritius

Email: myres.orc@gmail.com

Full paper submissions are invited for the 2020 International Conferences on Multidisciplinary Research to be held as a VIRTUAL conference in Mauritius from $14^{\text {th }}$ to $15^{\text {th }}$ December 2020 from the Voila Hotel, Bagatelle. All papers will be double-blind reviewed and published in a conference proceeding with ISBN: 978-99949-0-615-4.

\section{IMPORTANT DATES}

Deadline for Paper Submission: Oct 31, 2020

Acceptance Notification:: Nov 10, 2020 Submission of Final Paper: Nov 20, 2020 Early registration starts on: Nov 01, 2020 Early Registration closes on: Nov 30, 2020

Late registration starts on: Dec 01, 2020 Late Registration closes on: Dec 10, 2020 